\title{
ENHANCING ELDERLY HEALTH AND WELLBEING THROUGH THE TRUE REVIVAL OF SUN AND WIND ARCHITECTURE
}

\author{
Mahshid Ghaeeni \\ Design Associate Architect at Michael Baker International, LEED AP BD+C, WELL AP, Master of Architecture, \\ Southern Illinois University, Carbondale, IL, US.
}

\section{Research Article \\ PII: S238315532100002-10 \\ Received: 15 April 2021 \\ Revised: 10 June 2021 \\ Published: 15 June. 2021}

Corresponding author:

E-mail:

mahshid.ghaeeni.74@gmail.com

\begin{abstract}
With the indication of the rapidly aging population, it is imperative that we start planning now for how we will house and care for the senior population in the future. Retirement living providers continue to expand wellness, dining, and recreation options in response to demands for more choices and a healthier lifestyle. Options that emerged at the beginning of the century continue to develop, to provide a healthier place for the elderly. Traditional life-care models of retirement living are being challenged by more flexible entry criteria, and transition to such a community is being handled in new and novel ways. The purpose of this paper is to show that creating a senior-living facility that is integrated sustainably with their natural environments is important because it has a significant impact on improving seniors' mental health and preventing their dehumanization within institutions. With the shift in the design of senior living facilities in recent years, this paper shows how effective design can bring in positive results in geriatric mental and physical well-being and prevents the dehumanizing feeling that institutional settings often impose. New models of elderly care significantly affect healthcare outcomes, especially through designs highly integrated with nature, sun, and wind. This article will focus on how to improve the connection of indoor spaces with surrounding environment, how to consider the available natural resources in design of senior-living residence while preventing the dehumanization of patients, retaining a fulfilling community for elderly care, and ensuring sustainability.
\end{abstract}

KEYWORDS: Senior Living, Elderly, Architecture, Nature, Daylight, Wind Direction, Sustainability, Living Building Challenge, WELL Certified Building

\section{INTRODUCTION}

Although communication with friends and families across the world is virtually effortless with advanced technology and the connectedness it brings, as a society, we are lonelier and feeling less connected than ever. Perhaps no other age group feels the keen sting of loneliness more than the elderly. Less social connection, physical weakness, movement difficulties, and transportation challenges can result in isolation for older adults. This isolation eventually can lead to loneliness, which has a destructive impact on health and quality of life. Senior Living Centers are places that can help the elderly stay socially connected and receive all the comforts of home, plus the focused attention that comes from personal care services. However, living in a community is not enough to counteract the potential effects of loneliness and other social ills. Human needs balanced environments that connect them to nature. Connection to nature and natural systems is a prescribed healer of stress and has the potential to increase life span. The sustainable design process for senior living communities should embrace this idea as a "natural medication," and it's something that needs to be kept top of mind when designing for seniors.

Care for the elderly can be fostered consciously through meaningful architectural design. This paper focuses on analyzing a vital and healthy assisted senior-living residence for $65^{+}$seniors that integrates the needs of living in a community with the health benefits that come from a deep connection to nature, sun radiation, and wind direction. This research will illustrate how architectural design can be an effective tool for problem-solving, respond to every community's needs, and is a crucial factor in creating a durable and stable environment for seniors.

The goal of this research is to explore the relationship between living spaces and nature. The roles of sunlight and wind are analyzed in enhancing design to promote better performance standards. This research will explore models that encourage newer aesthetic approaches that seek to highly integrate natural features with living spaces. 


\section{Human- Nature - Architecture}

Nature has been a focus on the human mind from prehistoric times. All over the world today, from indigenous tribes to urban metropolises, human lives are intertwined with the environment around them. Separation of the individual and nature is impossible. On the other hand, efficient immersion of human dwellings with nature can facilitate personal healing and growth.

Questions surrounding the origins of human attachment to nature have fascinated the minds of many academics. The evolutionary biologist E.O. Wilson provided one answer. His theory of "biophilia" states that humans are drawn to nature experiences due to evolution. The abundance of resources found in natural environments fostered an evolutionary attachment in the human mind to nature. These desires were driven by the human need for survival and the entity that provides for humanity-nature. Thus, when human civilization began, and societies began to urbanize, architecture also intertwined itself with nature [1].

History has shown us that environments and climates shape their respective human settlements. Design and urban organization in every city heavily adjust to the surrounding forces of nature. Up until fairly recently, architectural design and human relationships to places were dependent on the forces of the sun and wind to sustain life. However, within the last century, humans have freed themselves from this dependency by using fossil fuels, electric lighting, and ventilation. A side effect of this process has been the loss of natural forces as the main formgivers. Alienation from nature has become the norm. Our cities no longer coexist with their environments but rather try to outgrow their surroundings. Many cities focus on gaining autonomy through a fossilfuel paradigm. Even though much ecological progress has been made lately in sustainable design, it is still dependent on improving fossil fuel use to make it more efficient [2].

The recent call by architect Ed Mazria in the Architecture 2030 Challenge to move toward carbon-neutral design dramatically raises the bar for energy performance and demands profound changes in design thinking and practice. The looming threat of climate change behooves architects to change their role radically. The focus must be shifted towards making the design carbon-neutral. In order to solve our current ecological problems, sustainable design must also develop a broader ecological consciousness. Human dwellings need to be designed in a way that solves instead of contributes to environmental destruction. Architecture must view the sun and wind as active tools for design.
Ecological and sustainable benefits are effortlessly achieved by harnessing these two forces. Design that maximizes the sun and wind's power by viewing them as generative sources can optimize the integration of light and air, thus profoundly impacting health and well-being. An ecological relationship can only be created when the necessity of light and air in living spaces is truly acknowledged and realized. By considering how cities reflect the ecological relationship inhabitants have with nature, one can deduce and understand the collective history within a place. To progress beyond our current fossil-fuel paradigm, light and air must be brought mainly from the sun and wind once again to eventually eliminate dependency on unsustainable sources. Architecture is an essential bridge to this new ecological ethos with our natural surroundings [2].

\section{Light}

Light is an essential essence of architecture. Masterful usage of light can bring unrivalled harmony to space. It can be the difference between making the quality of an architectural space habitable or hostile. The concept of aesthetic beauty relies on the symbolic bond with light across all cultures. Light informs us how much activity a certain time of day calls for, and which mood a space accommodates. A potential reason for this can be due to how humans associate brightness with different times throughout the 24 hour day. Light can also be used to enhance feelings of relaxation and encourage productivity. One of the most potent characteristics of light is its capability to combat feelings of sadness. Different seasons are associated with varying levels of brightness, and as such, winter is seen as the darkest one. Lack of light during the winter months brings melancholy and depression. Thus, creating spaces that purposefully maximize the potential for light to enter directly affects our physiology [3].

An example of the effect of light upon an architectural space, as indicated in Figure 1 and Figure 2, is the presence of a large glass window that permits the entry of copious amounts of sunlight. Thus, the space feels roomy, making it breathable and liberating for inhabitants. Preventing the mind from feeling suffocated must be the goal of effective usage of light. Additionally, the more natural light is used, the less artificial light will be used; this reduction of artificial light diminishes energy waste. Another positive impact on our health further promoted by the addition of natural light is reducing eye strain. 
Humans are creatures of the day; the human's internal clock and health are dependent upon adequate exposure to sunlight [4]. Studies consistently show the impact of sunlight. Once the eyes are exposed to sunlight, a flood of the hormone cortisol fills the system, providing a boost to the body, thus essentially waking it up for the day. A dark space or one lit by artificial light cannot provide the same boost of energy. The constant exposure to artificial light that is common in today's world wreaks havoc on the body over long periods [5].

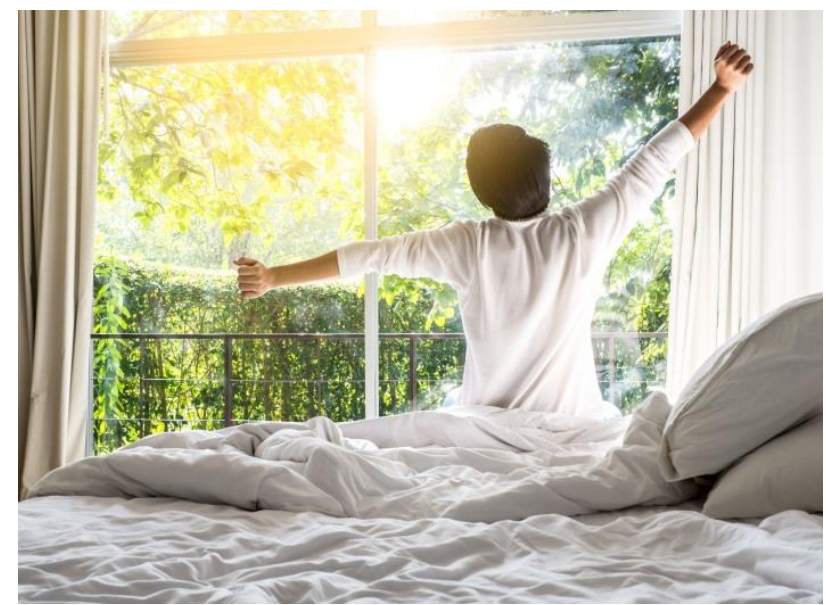

Figure 1. Bedroom with morning day light (Source: [5]).

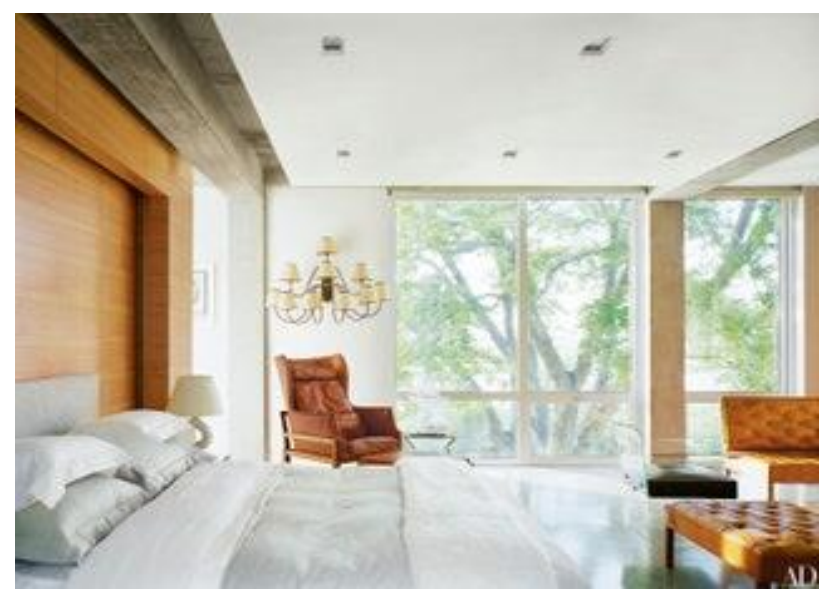

Figure 2. Daylight in the bedroom (Source: [5])

Serotonin is also another hormone that is activated by sunlight. It plays a role in depression regulation. As such, during the winter months, when sunlight exposure is decreased, seasonal depression becomes dominant. An increased amount of serotonin is associated with improved, better and happier moods. Providing more natural light can directly target seasonal depression. Also, the quality of sleep and the production of vitamin D are affected by sunlight. Our bodies are engineered to be in tune with the sun. Furthermore, the ability of sunlight to bring warmth can be a sustainable method of temperature control in spaces. The reduction of energy waste is imperative now more than ever when the threat of climate change is imminent. How much light is allowed inside space should be optimized according to energy efficiency and temperature [4].

To understand light's role in human physiology and psychology, one must know the circadian rhythm. Human bodies react to the amount of light the sun emits at different hours of the day. At dawn, the body is at its coolest temperatures, and as the day progresses, it releases cortisol to energize the body. The body's temperature peaks at noon and once again cools down at dusk. In the evening, the reduction of light signals to the brain prepares the body for sleep by releasing melatonin. However, with tech devices and screens cementing their positions as permanent fixtures in everyday life, artificial light interferes with the circadian rhythm's natural cycle. Thus, bright light exposure at dark hours prevents melatonin production and prevents our bodies from producing restful sleep. Over time, this constant disruption can wreak havoc on physiological and psychological health [6].

For my masters' thesis, I designed a Senior Living Facility in Rockville, Maryland. I conducted a comprehensive review of circadian rhythms in older adults alongside a site analysis to determine which direction provides the maximum advantage from daylight (Figure 4 shows building component allocation based on this study). As indicated in Figure 3 and 4, the sleeping rooms are located on the South-East and south side of the building to get maximum benefit of morning daylight till noon. The ground floor offices are located on the southeast too since it has light from morning to afternoon. Dining areas are located in the west, as they get evening light, whereas breakfast areas get the advantage of morning daylight from the east and through the open courtyard.

\section{WIND}

The second factor in nature that plays a fundamental role in architecture is wind. Air circulation is necessary to provide healthy air for indoors. Air from the outdoors brings higher amounts of oxygen. Breeze offers the natural force that creates healthy breathing atmospheres.

We spend almost $90 \%$ of our time indoors, yet we may not know that the air quality is often poor and unhealthy. The stuffiness of an indoor space can be exacerbated if the air inside is not consistently circulated. A stagnant flow of air will make the presence of allergens and dangerous microscopic 
pollutants remain in a space for extended periods of time, posing a risk for inhabitants. A replenishing of air through wind will benefit health by ridding the indoor air of contaminants that have built up over time.

Incorporating natural ventilation has several advantages: low running cost, low energy consumption, low maintenance, and low initial cost. Additionally, its inherent integration with nature provides psychological benefits. The prevailing outdoor conditions are the main key element in determining the effectiveness of natural ventilation: microclimate (wind speed, temperature, humidity, and surrounding topography) and the building itself (orientation, number of windows or openings, size, and location). How much advantage is gained from natural ventilation throughout the year primarily depends on the design of fenestration and the arrangement of windows and doors on the elevations of a building [7].

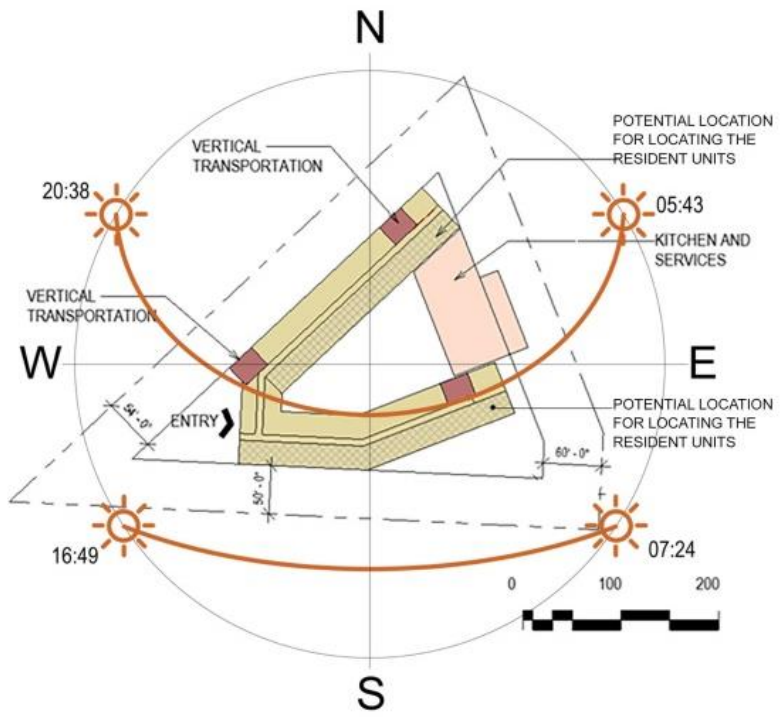

Figure 3. Building Form and Orientation (Source: By author - From thesis book)

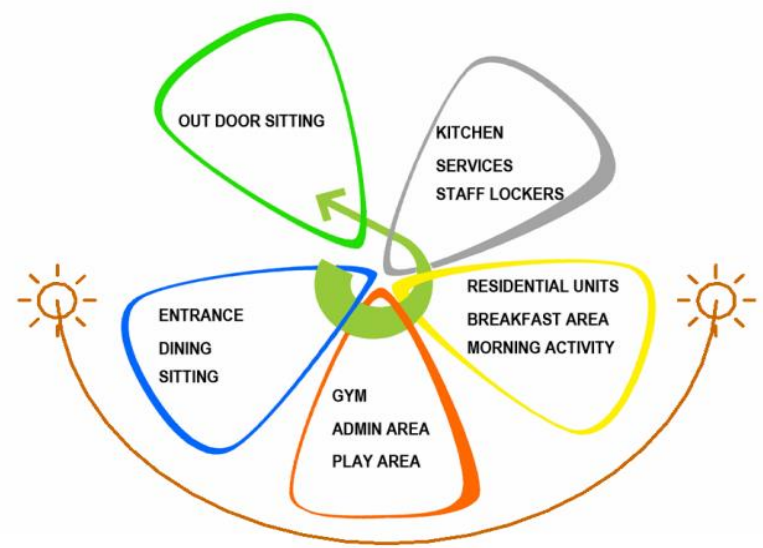

Figure 3. Building Component Allocation (Source: By author - From thesis book)

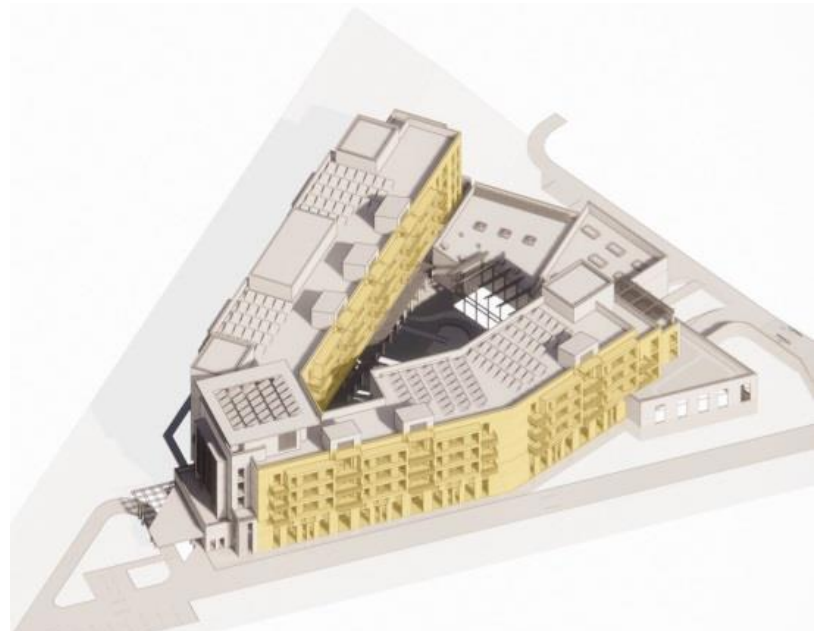

Figure 5. Location of Bedrooms on South and South-East (Source: By author - From thesis book)

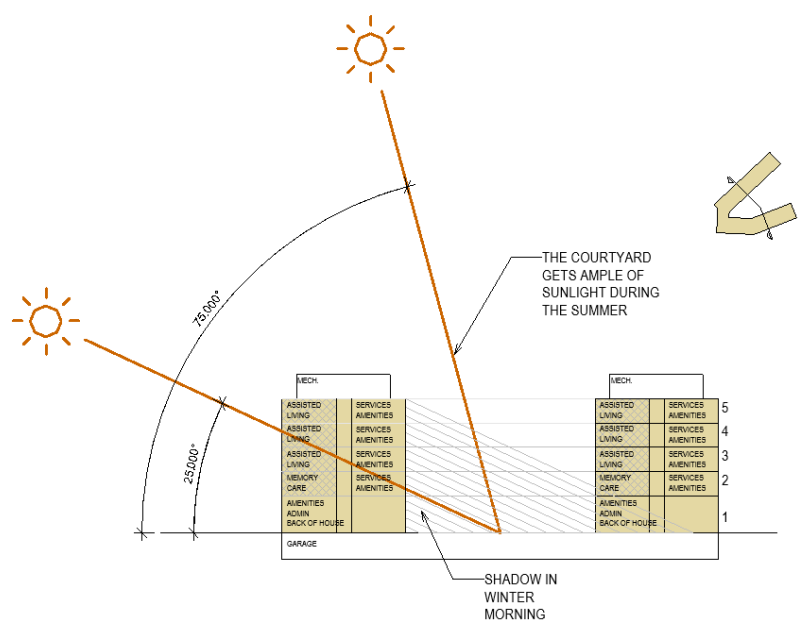

Figure 4. Section Diagram (Source: By author From thesis book)

\section{METHODOLOGY}

What can designers do to improve ventilation in nursing home?

Interior air quality is particularly important for frail seniors, who spend long periods of the day indoors. Consideration of two design strategies is required for having healthier indoor spaces: avoiding toxic material and providing efficient ventilation [8].

An air quality detector that can reliably measure $\mathrm{CO}_{2}$ levels is a simple step to achieve adequate ventilation. $\mathrm{CO} 2$ detector can demonstrate the air quality in each space and whether ventilation needs to be improved in the room. Most nursing homes are heated by reverse-cycle split-system air conditioners or warm air heating systems. These units do not introduce fresh air. Opening the windows to bring the fresh air in is essential for the well-being of residents, even though this may make maintaining a 
comfortable temperature more difficult. Creating a flow of warmed and filtered fresh air from central corridor spaces into rooms and out through windows would be ideal; however, it would probably require investment in mechanical ventilation. Using radiant heaters in rooms instead of recirculating heat pump air conditioners is one of the temporary solutions for improving the quality inside a room. Besides using a radiant heater, windows must open far enough to lower $\mathrm{CO}_{2}$ levels consistently below 850ppm in rooms and corridors [9].

\section{RESULTS AND DISCUSSION}

\section{Connection to nature as a healing factor for elderly}

When an elderly person is placed in a senior living facility, a sense of loss and shock may be felt. Moving from a familiar space to a new-sometimes even smaller, stifling-space can negatively affect mental health. For many seniors who are in delicate physical conditions, the design of their apartments must be approached with sensitivity to their wellbeing. The provision of a vista significantly diminishes feelings of isolation and loneliness. Living in a stuffy apartment suffocates the mind. Large windows provide the additional comfort of a view. Feeling a connection to nature is a fundamental need of humanity. Through a wide view, the indoor space will not feel brutally disjointed from an outdoor space. The mind must also be in harmony with the outside space and with the inside one.

Witnessing the coming and going of seasons prevents losing touch with nature. Isolation comes in many forms, each of which devastates equally and mercilessly. Designs must cater to the innate human need for connection. Not seeing the changes that take place around oneself can unwittingly make one feel as if they have been ostracized from society and that the world at large has shoved them away to a corner as if their presence burdens others. In the same way a key driver of social isolation is unawareness of new developments in the lives of those around oneself, unawareness of the cyclical changes in nature compound upon other isolating forces in senior living facilities.

A University of Michigan study looked at the link between "lower depression" and "enhanced mental well-being" and frequent walks in nature. The results showed that the participants who spent more time in nature had better overall health, lower blood pressure, and reduced stress than those who did not spend significant amounts of time out in nature.
Also, spending more time outside can produce higher levels of Vitamin D in humans. Even if the time spent outside is short, studies show that individuals exposed more to nature have better overall energy levels and moods. In many elderly adults, studies have shown frequent walks in nature have a strong correlation with improvement in memory retention. By offering a distraction to our minds through nature, humans can allocate more energy and time to tasks that require focus and memory [10]. Rates of cardiovascular disease and sleep disorders are much lower amongst people who dedicate part of their day to interacting with nature. Overall, health outcomes tend to be higher in these people. Adults that enjoy nature more also live longer on average. This can be attributed to how spending time outdoors requires a higher amount of physical activity. Moreover, other studies have demonstrated that elderly adults that spend more time interacting with nature have better immune systems [10].

An example of beneficial interaction with nature for older adults is therapeutic horticulture (TH). TH consists of activities in which participants are involved in gardening to improve their mental and physical health specifically. Since many studies have shown its positive impacts on the well-being of elderly health, it has been rapidly gaining popularity in many senior living spaces. TH has been linked in some studies with lower levels of anxiety and depression and reduced feelings of alienation [11].

Open courtyards and roof gardens are two promising outdoor design strategies that need to be considered in the design of senior facilities. According to a National Research Council of Canada study, Roof gardens result in cost savings in many ways. During summer, rooftops become excessively hot, sometimes hitting 150 degrees Fahrenheit. Thus, they create a need for more air-conditioning. Whereas in winter, roofs allow heat to escape, depriving buildings of retaining warmth. The installation of a roof garden serves as a form of thermal insulation [12]. A common belief is that seniors must give up gardening and other outdoor hobbies once they move into a senior living community. However, the reality does not need to be as dour. Senior living homes can provide gardens to ensure seniors still have the ability to interact with nature. As for seniors who do not have prior experience with gardening, it can be a new hobby for them to pick up and entertain themselves once they move into a facility. One specific type of gardening that is particularly useful for senior living communities is vertical farming. It consists of 
growing herbs and plants on platforms stacked above each other in order to optimize both the amount of space and nutrients used. These elevated platforms allow for more creative gardening and support any mobility issues a senior might have, as it does not require bending or difficult maneuvers. Pots that go into these platforms can be placed on a table and later placed in the platforms, thus also accommodating seniors confined to seated positions.

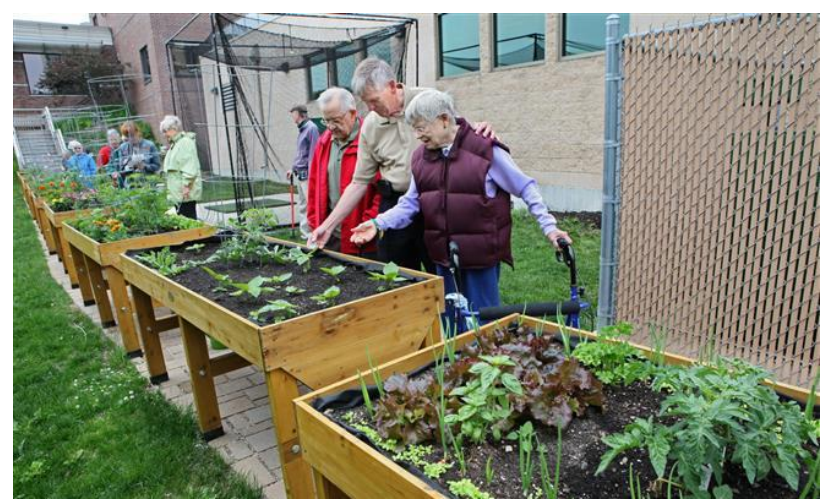

Figure 5. Gardens keep seniors busy at St. John's on the Lake [11].

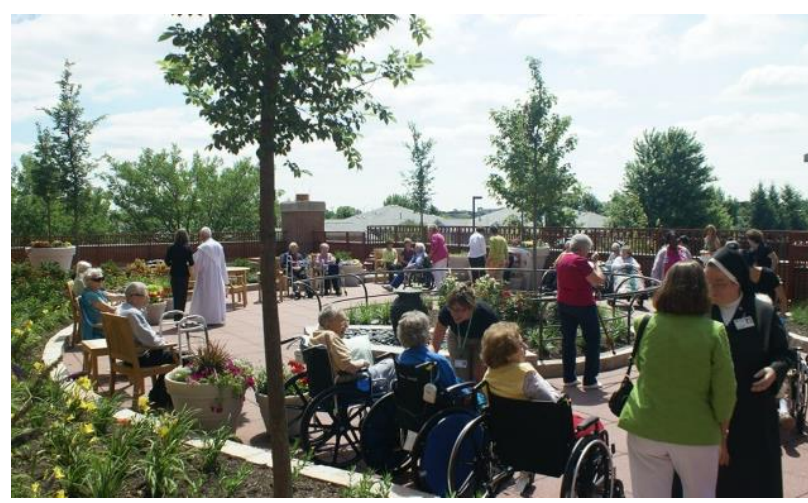

Figure 6. Roof Gardens at St. Patrick's Residence, Naperville [11].
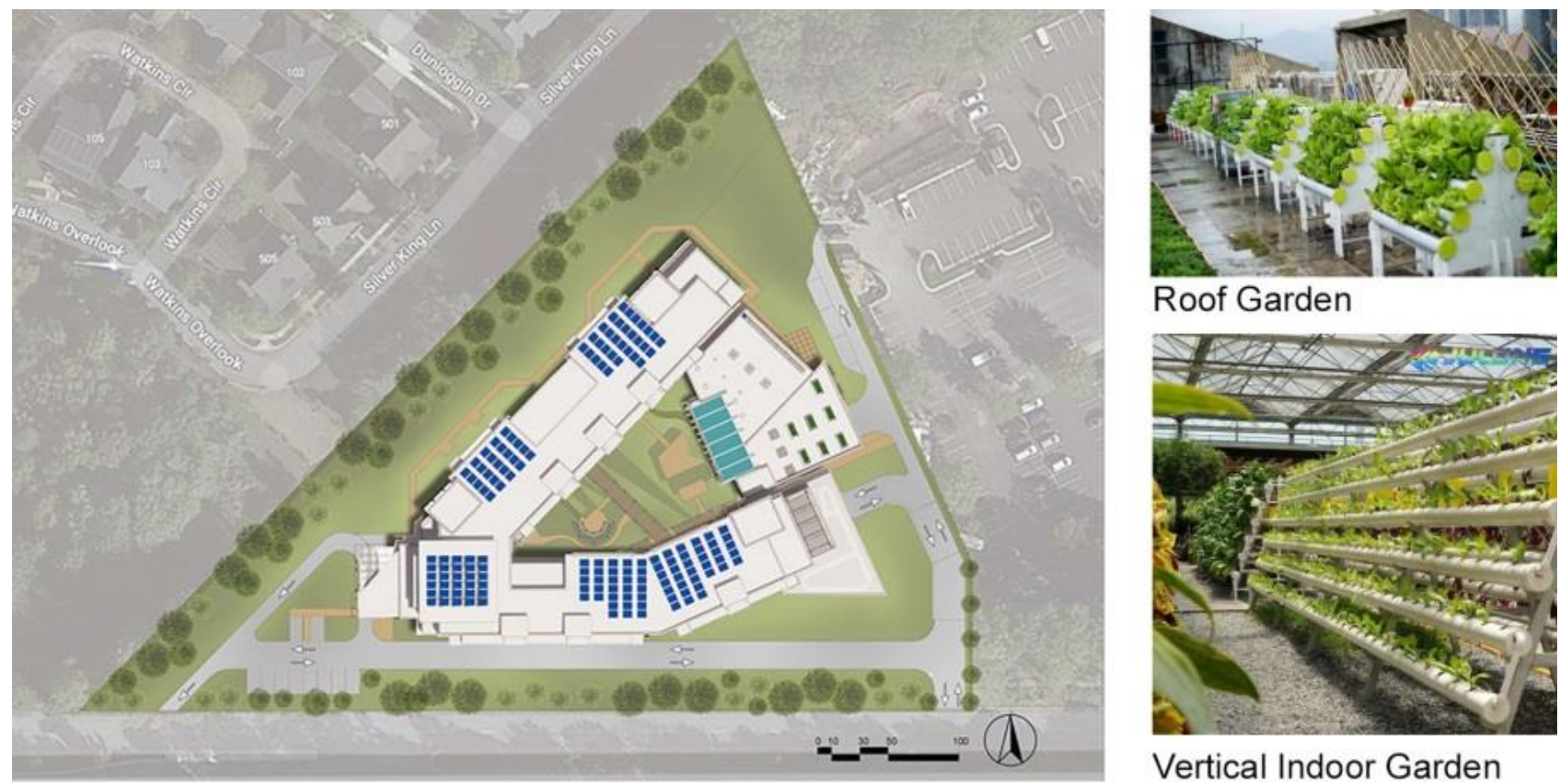

Vertical Indoor Garden

Figure 7. Roof Garden and Indoor Vertical garden can serve as a self-sufficient source of legumes for the facility (Source: By author - From thesis book).

\section{Sustainable Architecture Strategies}

A marker of a society's advancement is how much sustainability is incorporated into design strategies. Since the beginnings of the notion of sustainability in the late 80 , focus has also been placed upon individuals' mental well-being rather than solely on the effect of designs on the local environment and economy. A human-centered approach has become central to sustainability. Thus, sustainability has also started to focus on the quality of life for seniors. As populations in countries gradually age, sustainable design strategies more closely examine how to be more accommodating of senior populations as well.

LEED is one of the most used sustainability certification programs which provides a framework for healthy, highly efficient, and cost-saving green buildings [13]. Access to nature (connecting building occupant with outdoor), reinforce circadian rhythms through (considering sun direction in design), introducing daylight into space, and natural and hybrid ventilation can help the building project earn points under the LEED certification program. 
The following categories contain opportunities to earn points under the LEED certification program by incorporating nature, sun, and wind into the design [13]:

- Sustainable site

- Energy and atmosphere

- Materials and resources

- Indoor environmental quality

- Regional priority

Points could be earned when evaluated the following within the above categories [13]:

- Heat island reduction

- Minimum energy performance

- Optimize energy performance

- Demand response

- Building life-cycle impact reduction

- Minimum indoor air quality performance

- Enhanced indoor air quality strategies

- Thermal comfort

- Interior lighting

○ Daylight

- Quality views

- Regional Priority: Renewable Energy

Production

While LEED places its focus on the impact of buildings in relation to sustainability, WELL focuses on people's health within the building and promote the health of the human body, including its cardiovascular, immune, and respiratory systems. Like in the LEED system, points are earned through optional credits and all mandatory credits must be met. WELL certification is based on ten performance categories [14]: Air, Water, Nourishment, Light, Movement, Thermal Comfort, Sound, Materials, Mind, and Community. Each category consists of features with distinct health intents. Features are either preconditions or optimizations. Exposure to appropriate amounts of natural light, limiting pollutant and contaminant concentrations, access to fresh fruits and vegetables, neighborhood walkability, and connectivity will help to earn points under all of the WELL categories [14].

The Living Building Challenge is another internationally acknowledged building rating system that visualizes the built environment ideal. It uses the metaphor of a flower because the ideal built environment should function as cleanly and efficiently as a flower [15]. Nowadays, the demands upon what spaces must provide to their occupants have changed. Spaces must now integrate multiple elements-mainly light, air, and community.
Elements of a space must function together to promote health, beauty, and well-being. The Living Building Challenge inherently requires these qualities.

\section{CONCLUSION}

\section{Promoting nature and well-being in the design of senior living facilities}

Aging should not necessarily inhibit one's mobility. Youth can more easily remain connected with nature by engaging in outdoor activities. Younger people can go for a stroll or ride a bike without requiring any additional assistance, making the elderly more prone to disconnecting from their environment. While retaining a similar level of engagement with nature is more difficult for the elderly, it does not have to be impossible. Senior living facility designers must utilize strategies to ensure a drastic decrease of connection to nature does not occur. One potential approach is Biophilic Design to facilitate a greater ease in remaining connected with the outside world for senior residents.

Biophilic design calls for the integration of nature, the sun, and the wind. By taking advantage of the generative sources already present in a site, the forces of the sun and wind can optimize light and air. To promote sustainability, an architect must enhance illumination and ventilation through fostering design rooted in incorporating naturally occurring light and air. By diminishing dependency on fossil fuels and instead using renewable sources, senior living facilities can coexist in harmony with their natural environments. Since one of the main roles of senior living facilities is to maintain seniors' health, maximizing illumination and ventilation balances a building's relationship with nature; thus, ensuring seniors can remain connected to their surroundings. A true architecture of the sun and wind strives to improve the social, psychological, and ecological health of a space and its occupants.

\section{Competing interests}

The author declares that there are no competing interests.

\section{REFERENCES}

[1] Green K, Keltner D (2017). What Happens When We Reconnect with Nature. The Greater Good Science Center at the University of California, Berkeley, https://scholar.google.com/scholar?hl=en\&as_sdt=0 \%2C39\&q=What+happens+when+we+reconnect+wit h+nature\&btnG $=$ 
[2] Guzowski M (2008). The New Architecture of the Sun and Wind. (AIA Committee on the Environment (COTE) Sustainable Design Whitepapers). https://scholar.google.com/scholar?hl=en\&as $\quad$ sdt $=0 \% 2 \mathrm{C} 39$ \&q=AIA+Committee+on+the+Environment $+\% 28$ COTE\%29 + Sustainable+Design + Whitepapers\&btnG $=$

[3] Van Uffelen C (2011). Light in Architecture. Salenstein, Switzerland: Braun Publishing AG; https://www.google.com/books/edition/Light in Ar chitecture/l2PxtgAACAAJ?hl=en

[4] Cushner K (2021). If you want better sleep, get more morning sunlight [Internet]. Tuck.com. https://www.tuck.com/sleep/importance-ofmorning-sunlight-for-better-sleep/

[5] Davis C (2014). Shining light on what natural light does for your body [Internet]. Ncsu.edu. https://sustainability.ncsu.edu/blog/changeyourstate /benefits-of-natural-light/

[6] National Institute Of General Medical Sciences. Circadian Rhythms (2020). [Internet]. Nih.gov. https://www.nigms.nih.gov/education/factsheets/Documents/fact-sheet-circadian-rhythms.pdf

[7] Bhatia A. HVAC - Natural Ventilation Principles [Internet]. Cedengineering.com. https://www.cedengineering.com/userfiles/HVAC\%2O\%20Natural\%20Ventilation\%20Principles\%20R1.pdf

[8] Perkins B, Hoglund JD, King D, Cohen E (2013). Building Type Basics for Senior Living. 2nd ed. John Wiley \& Sons; https://scholar.google.com/scholar?hl=en\&as_sdt=0
$\% 2 \mathrm{C} 39 \& \mathrm{q}=$ Building + Type + Basics + for + Senior + Living $\underline{\text { btnG }=}$

[9] Milthorpe B, Hanmer G (2020). Poor ventilation may be adding to nursing homes' COVID-19 risks. The Conversation [Internet]. http://theconversation.com/poor-ventilation-maybe-adding-to-nursing-homes-covid-19-risks-144725

[10] Companions for Seniors (2019). The healing power of nature for seniors [Internet]. Companionsforseniors.com.

https://companionsforseniors.com/2019/03/healingpower-nature-seniors/

[11] Demski JK (2014). Gardens keep seniors busy at St. John's on the Lake [Internet]. Jsonline.com. http://archive.jsonline.com/features/garden/gardens -keep-seniors-busy-at-st-johns-on-the-lakeb99292849z1-264782321.html

[12] Liu KK (2002). Energy efficiency and environmental benefits of rooftop gardens. Construction Canada. https://scholar.google.com/scholar?hl=en\&as_sdt=0 \%2C39\&q=Energy+efficiency + and +environmental $+\mathrm{b}$ enefits+of+rooftop+gardens $+\& b \operatorname{tnG}=$

[13] USGBC. What is LEED? [Internet]. Usgbc.org. https://www.usgbc.org/help/what-leed

[14] International WELL Building Institute (2021). WELL V2TM Overview [Internet]. Wellcertified.com. https://v2.wellcertified.com/wellv2/en/overview

[15] Living Building Challenge (2016) [Internet]. Livingfuture.org. https://living-future.org/lbc-3_1/basics/ 